\title{
O DIREITO À INFORMAÇÃO E O EXERCÍCIO DA CIDADANIA NA SAÚDE
}

\section{RIGHT TO INFORMATION AND CITIZENSHIP IN HEALTH}

\author{
James MAXWell Fernandes Araujo \\ Doutor em Comunicação Social pela Universidade Metodista de São Paulo (UMESP), mestre em Ciência da Informação \\ pela Universidade de Brasília (UnB) e Graduado em Comunicação Social pela Universidade Federal do Maranhão \\ (UFMA). Exerce o cargo de professor adjunto no Departamento de Comunicação Social da UFMA. \\ jamesmfa@uol.com.br
}

\begin{abstract}
RESUMO
Aborda a prática da cidadania, por meio do exercício do direito à informação na área da saúde e os fundamentos teóricos da sua construção. Analisa os aspectos jurídicos do direito à informação na sociedade e nas instituições de saúde. Observa como as características da comunicação interpessoal entre o médico e seus pacientes podem influenciar no exercício do direito-meio - direito à informação e, por extensão, do direito-fim - direito social à saúde. Explica os modelos de interação médico-paciente, particularmente os modelos paternalista, informativo e comunicacional. Enfatiza a importância do modelo comunicacional, que se dá a partir da negociação, do compromisso recíproco e do respeito às particularidades pessoais de cada paciente. Esta concepção de relacionamento interpessoal representa uma proposta de ruptura com os modelos paternalista e informativo, pois consiste em novas formas de interação, não apenas de médicos e pacientes entre si, mas também entre os profissionais e a sociedade.
\end{abstract}

Palavras-chave: cidadania; direito à informação; comunicação médico-paciente.

\begin{abstract}
Addresses the practice of citizenship, through the exercise of the right to information on health and the theoretical foundations of its construction. Analyses the legal aspects of the right to information in society and in health institutions. See how the characteristics of interpersonal communication between the physician and his patient may influence the exercise of the right-half - right to information and, by extension, the right-end - social right to health. Explains the models of doctor-patient interaction, particularly patronizing, informative and communication models. It emphasizes the importance of communication model, which starts from the trading, mutual commitment and respect to the personal characteristics of each patient. This conception of interpersonal relationships is a proposal to break with the paternalistic and informative models because it consists of new forms of interaction, not just doctors and patients to each other, but also between professionals and society.
\end{abstract}

Keywords: citizenship; right to information; doctorpatient communication. 


\section{SUMÁRIO}

INTRODUÇAO; 1 A INFORMAÇÃO E A COMUNICAÇÃO NA SOCIEDADE; 2 OS FUNDAMENTOS DO DIREITO À INFORMAÇÃO; 3 AS FORMAS DE INTERAÇÃO ENTRE O MÉDICO E O PACIENTE E SUA INFLUÊNCIA NO EXERCÍCIO DA CIDADANIA; CONCLUSÃO; REFERÊNCIAS.

\section{INTRODUÇÃO}

O importante momento histórico de construção da cidadania, atribuída ao surgimento da vida na cidade e à capacidade de os homens exercerem seus direitos e deveres ${ }^{1}$ foram objeto das reflexões pioneiras desenvolvidas por Marshall ${ }^{2}$. Ao dividir o conceito de cidadania, ele propôs três elementos ou partes, sendo uma civil, outra política e a terceira chamada de social. Formado pelos direitos necessários à liberdade individual, à liberdade de ir e vir, entre outras, está o elemento civil. A parte política, por sua vez, diz respeito ao direito de participação no processo político, seja como membro de determinado organismo ou como eleitor dos respectivos membros. O elemento social está relacionado ao que abrange os direitos ao mínimo de bemestar econômico, segurança, educação, saúde, etc.

No campo específico da saúde, a evolução social e política que integra a construção da cidadania também determinou a consolidação dos direitos dos usuários dos serviços de saúde, inseridos particularmente na esfera dos direitos sociais e dos direitos civis. Os primeiros dizem respeito ao atendimento de todas as necessidades humanas indispensáveis à sustentação do corpo humano, as quais são fundamentais para a reposição da força de trabalho. E apenas com a promulgação da Constituição Federal de 1988, o direito à saúde passou a ser considerado, por meio do Título VIII, da Ordem Social; Capitulo II, da Seguridade Social, Seção II, artigo 196³, como direito fundamental do indivíduo e dever do Estado.

Os direitos civis, por sua vez, representam um fator de grande importância, sobretudo ao assegurar ao cidadão o direito de dispor do próprio corpo no que diz respeito à sua locomoção, segurança e saúde. Para Gauderer ${ }^{4}$, a discussão dos direitos do paciente não deve se resumir à

\footnotetext{
${ }^{1}$ COVRE, Maria de Lourdes Manzini. O que é cidadania. São Paulo: Brasiliense, 1993. p. 16.

${ }^{2}$ MARSHALL, T. H. Cidadania, classe social e status. Tradução de Meton Porto Gadelha. Rio de Janeiro: Zahar, 1967. p. 123.

${ }^{3}$ BRASIL. Constituição Federal. Brasília: Senado Federal, 1988

${ }^{4}$ GAUDERER, Christian. Os direitos do paciente: cidadania na saúde. Rio de Janeiro: Record, 1998. p. 26.
} 
elaboração de listagens abstratas de direitos dificilmente exercidos. Ela deve discutir a prática cotidiana da medicina e a forma com nascem novos direitos em uma relação entre dois cidadãos.

Houve uma mudança radical, dramática, fundamental na relação do indivíduo com sua doença e seu corpo, e esta evolução advém de progressos que a medicina fez principalmente na segunda metade deste século. Os conhecimentos médicos foram e estão sendo cada vez mais democratizados, tornados públicos e divulgados. Os jornais, rádios, televisões, livros e revistas, além de organizações particulares diversas, têm, de maneira séria e sistemática, esclarecido e educado a população sobre os problemas de saúde os mais diversos. Não fomos nós, médicos, que demos este passo no sentido de educar e conscientizar a população. Essa postura nasceu como uma exigência dos pacientes e de seus familiares, a reboque dos movimentos dos direitos humanos, por sua vez, uma consequência dos movimentos de democratização e igualdade entre os homens ${ }^{5}$.

Lembramos que, a partir de 1968, a produção científica e encontros, sobretudo, congressos sobre ética médica tiveram crescimento expressivo, o que influenciou de forma significativa os movimentos da sociedade civil. Isso ajudou a desenvolver uma consciência sobre os direitos individuais e a criar o repúdio ao paradigma da dominação e controle pelo saber e fazer médicos.

Para Sueli Dallari, é necessário encontrar o meio de garantir efetivamente o direito à saúde, pois não basta apenas declarar que todos têm direito a ela. "É indispensável que a Constituição organize os poderes do Estado e a vida social de forma a assegurar a cada pessoa o seu direito. É função de todo profissional ligado à área da saúde contribuir para o debate sobre as formas possíveis de organização social e estatal que possibilitem a garantia do direito à saúde"6.

No Brasil, a $8^{\text {a }}$ Conferência Nacional de Saúde, ocorrida em 1986, pode ser considerada como um marco, não apenas na redemocratização da sociedade, mas também na consolidação de uma nova conjuntura no campo da gestão pública, pois suas principais deliberações produziram profundas influências nos trabalhos da Assembleia Nacional Constituinte, instalada no ano seguinte e, por extensão, na Carta Magna de 1988.

\footnotetext{
${ }^{5}$ GAUDERER, Christian. Os direitos do paciente - cidadania na saúde. Rio de Janeiro: Record, 1998. p. 63. ${ }^{6}$ DALLARI, Sueli Gandolfi. 0 direito à saúde. Revista de Saúde Pública. São Paulo, 22(1):57-63, 1988. p. 60.
} 
0 primeiro ponto estabelecido pela $8^{a}$ CNS, que, de forma inédita, reuniu não apenas médicos, técnicos e intelectuais do setor, como também representantes dos usuários dos serviços, sindicatos, associações e entidades religiosas, foi declarar a saúde como direito de cidadania e dever do Estado, e não mais como direito que se adquire pelo trabalho. Esta nova concepção “implica uma visão desmedicalizada da saúde, na medida em que subentende uma definição afirmativa (positiva), diferente da visão tradicional, típica das instituições médicas, que identifica a saúde com ausência relativa de doenças"7.

No contexto dessa nova definição, a noção de saúde tende a ser socialmente percebida como efeito real de um conjunto de condições coletivas de existência, como expressão ativa - e participativa - do exercício de direitos de cidadania, entre os quais o direito ao trabalho, ao salário justo, à participação nas decisões e na gestão de políticas institucionais, etc. Assim, a sociedade teve a oportunidade de superar politicamente a compreensão, até então vigente ou socialmente dominante, da saúde como um estado biológico abstrato de normalidade (ou de ausência de patologias).

As primeiras proposições da $8^{\mathrm{a}}$ CNS já consideravam a educação, a comunicação e a informação como pré-requisitos do exercício do direito à saúde e da cidadania. A partir da $9^{a}$ Conferência Nacional de Saúde, por sua vez realizada em 1992, os temas comunicação e informação foram uma constante nas pautas de discussão sobre a questão do controle social das instituições públicas, e no $10^{\circ}$ encontro, de 1996, ficou explícito o apoio à democratização dos meios de comunicação.

Torna-se evidente, portanto, que os desdobramentos desse processo democrático de construção da cidadania têm como um dos seus principais ingredientes o atendimento do direito à informação em suas várias manifestações. Marques de Melo ${ }^{9}$ afirma ser esta uma categoria em processo de configuração, situada na fronteira entre o direito de comunicação (liberdade de expressão e de pensamento) e o direito de educação (aprendizagem do conhecimento acumulado, do saber estocado).

\footnotetext{
${ }^{7}$ LUZ, Madel Terezinha. As conferências nacionais de saúde e as políticas de saúde da década de 80. In: GUIMARÃES, Reinaldo; TAVARES, Ricardo (Orgs.). Saúde e sociedade no Brasil, anos 80. Rio de Janeiro: Relume-Dumará/IMS-UERJ, 1994. p. 82.

${ }^{8}$ Ibidem, p. 82.

${ }^{9}$ MELO, José Marques de. Comunicação: direito à informação. Campinas: Papirus, 1986. p. 69.
} 


\section{A INFORMAÇÃO E A COMUNICAÇÃO NA SOCIEDADE}

A coexistência destes dois fatores - informação e comunicação - representa um ponto pacífico nas abordagens de diversos autores, sejam aqueles circunscritos ao campo específico da ciência da informação ou entre os pesquisadores atuantes no âmbito da ciência da comunicação. Entre os primeiros, Saracevic ${ }^{10}$ estabelece a distinção entre informação, enquanto fenômeno, e comunicação, como processo. Além disso, enfatiza a importância dos estudos sobre as relações entre ambas, uma vez que cada conceito atua de forma complexa sobre o outro. Ele define a ciência da informação como:

$\mathrm{m}$ campo dedicado às questões científicas e à prática profissional voltadas para os problemas da efetiva comunicação do conhecimento e de seus registros entre os seres humanos, no contexto social, institucional ou individual do uso e das necessidades de informação ${ }^{11}$.

O âmbito de atuação desta emergente ciência se configura a partir da responsabilidade de viabilizar a comunicação de mensagens entre emissores e receptores humanos. Tal atributo torna intrínseco o seu objeto de estudo ao universo dos fenômenos da comunicação social e, em particular, da comunicação de informações, com o objetivo de promover mudanças nas estruturas de conhecimento do receptor ${ }^{12}$. As relações fundamentais entre informação e comunicação confirmam o caráter social de ambas. A informação se afirma, como tal, enquanto resultado da produção do conhecimento e da atividade simbólica do homem no processo de interação com sua comunidade. A comunicação, que tem o social na sua própria etimologia tornar comum, compartilhar, representa a própria transação de troca de informação.

Uma das definições básicas de comunicação a apresenta como "uma das formas pelas quais os homens se relacionam entre si. É a forma de interação humana realizada através do uso de signos" ${ }^{213}$. O autor destaca, como característica da sociedade tradicional, o processo da

\footnotetext{
${ }^{10}$ SARACEVIC, Tefko. Ciência da informação: origem, evolução e relações. Perspectivas em Ciência da Informação, Belo Horizonte, v.1, n.1, p.41-62, jan./jun., 1996. p. 19.

${ }^{11}$ Ibidem, p. 47.

12 FREIRE, Isa Maria. Informação - consciência possível - campo: um exercício com construtos teóricos. Ciência da Informação, Brasília, v.24, n.1, p.133-142, jan-abr 1995. p. 133.

${ }^{13}$ BORDENAVE, Juan E. Diaz. Além dos meios e mensagens - introdução à comunicação como processo, tecnologia, sistema e ciência. Petrópolis: Vozes, 1993. p. 12.
} 
comunicação interpessoal e enfatiza sua revitalização, em razão da luta pelo fortalecimento da sociedade civil, onde o homem estaria reaprendendo a comunicação pessoa a pessoa ${ }^{14}$.

O caráter interdisciplinar desta abordagem, vale enfatizar, não se restringe à duas áreas acima definidas, a informação e a comunicação, pois a problemática que envolve os estudos sobre a informação no âmbito dos fenômenos da comunicação humana não pode ser elucidada dentro de poucas áreas da atividade científica. É indispensável o desenvolvimento de abordagens teóricas e metodológicas que permitam o relacionamento teórico entre vários campos.

Dentre os avanços obtidos na área dos direitos em saúde, para retomarmos o assunto, merecem destaque os principais instrumentos legais, instituídos com a finalidade de balizar a atuação dos profissionais e das organizações de prestação de serviços médicos. Regulamentado pelas resoluções 1.246/1988 e 1.617/2000, do Conselho Federal de Medicina, respectivamente, encontram-se em vigor o Código de Ética Médica e o Código de Processo Ético-Profissional. Chama a atenção, particularmente, o capítulo $V$ do Código de Ética Médica, que em seu artigo 59 afirma ser vedado ao médico:

Deixar de informar ao paciente o diagnóstico, o prognóstico, os riscos e objetivos do tratamento, salvo quando a comunicação direta ao mesmo possa provocar-lhe dano, devendo, nesse caso, a comunicação ser feita pelo seu responsável legal ${ }^{15}$.

Ao assegurar, na forma da lei, o direito à informação na relação médico-paciente, a referida legislação corrobora a importância de um dos principais fatores de desenvolvimento social e qualidade de vida. Pedro Demo ${ }^{16}$ propõe o conceito de cidadania emancipada, em que a sociedade torna-se capaz de conceber e efetivar seu projeto próprio de desenvolvimento. Indispensável a esse processo de emancipação e de construção da cidadania é o livre acesso à informação, que representa o principal estímulo ao questionamento crítico, o qual precede todo curso emancipatório.

\footnotetext{
${ }^{14}$ Idem. O que é comunicação. São Paulo: Brasiliense, 1985. p. 22.

${ }^{15}$ Conselho Federal de Medicina - Código de Ética Médica: resolução CFM n ${ }^{\circ} 1.246 / 88$ - Código de Processo Ético-Profissional: resolução CFM n 1.617/01 - Brasília: CFM, 2001. p. 24.

${ }_{16}$ DEMO, Pedro. Cidadania e emancipação. Revista Tempo Brasileiro, Rio de Janeiro, 100, 53-72, jan./mar., 1990. p. 62.
} 
A desigualdade social é marca estrutural de toda sociedade, o que leva ao entendimento de que cidadania e emancipação consistem no processo histórico de confronto entre iguais e desiguais $^{17}$. É na habilidade com que cada sociedade maneja e administra essa desigualdade que reside o teor de sua cidadania, fazendo dela mais ou menos cidadã. A busca do estado de justiça social que acompanha esse processo está associada ao modo como a informação é produzida e utilizada, de acordo com o princípio da pirâmide informacional ${ }^{18}$.

$\mathrm{Na}$ base da pirâmide informacional consta a informação como matéria, chamada de dados, ou seja, simples registros icônicos, simbólicos ou sígnicos. No segundo patamar da estrutura está a informação, na condição de material organizado de maneira potencialmente significativa. No terceiro nível encontramos o conhecimento, entendido como informação enquanto compreensão. Trata-se, esta última, de informação inteligível por qualquer indivíduo que domine o código linguístico e tenha respectiva base cognitiva para tal.

No topo da pirâmide encontramos o aspecto mais inerente ao processo de construção da cidadania, pois diz respeito aos desdobramentos sociais do uso progressivo e sistemático da informação. 0 patamar chamado de inteligência (que podemos traduzir também como saber) é entendido por "informação como oportunidade" ${ }^{19}$ e diz respeito às estruturas de conhecimento que possibilitam intervenções na realidade social. Um dos indícios de como a informação pode evoluir conforme demonstrado acima, ou seja, enquanto meio de exercício do poder, capaz de intervir no curso dos acontecimentos sociais, pode ser observado na proposição de leis, tais quais as que asseguram o respectivo direito legal à informação.

\section{OS FUNDAMENTOS DO DIREITO À INFORMAÇÃO}

Como porta de acesso a outros direitos, o direito à informação também suscita as condições para o processo de igualização dos indivíduos, além de possibilitar formas de

\footnotetext{
17 Ibidem, p. 53.

18 URDANETA, Iraset Páez. Gestión de la inteligencia, aprendizaje tecnológico y modernización del trabajo informacional: retos y oportunidades. Caracas: Instituto de Estudios del Conocimiento de la Universidad Simon Bolivar - Consejo Nacional de Investigaciones Cientificas y Tecnologicas, 1992. p. 100.

19 Ibidem, p. 103.
} 
visibilidade ao poder e ao mundo ${ }^{20}$. Desta maneira, embora se configure como um direito-meio, ele representa, sobretudo, um direito em si. Deve, portanto, ser considerado como tal em toda a complexidade que caracteriza a questão dos direitos nas sociedades modernas. Isto, porque em todas as atuais formações sociais estruturadas como democracias representativas o direito à informação está intimamente relacionado com todos os outros demais direitos.

Victor Gentilli ${ }^{21}$ chama a atenção para a ausência de abordagens sobre o direito à informação nas reflexões tradicionais sobre cidadania, pois elas tratam apenas dos chamados direitos-fim, os quais representam os direitos de cidadania tomados no sentido estrito. Daí, surge o emprego da expressão direito-meio para designar aquele, cuja falta, impediria o exercício pleno dos demais. Compreende-se, desta forma, que o direito à informação não se realiza em si mesmo, em razão de que a informação não é concebida como um fator dotado de um valor em si mesmo.

Falar apenas em direito à informação esclarece pouco. Direito à qual informação? 0 direito à informação concebido como direito de cidadania é, exatamente, o direito àquelas informações necessárias e imprescindíveis para a vida numa sociedade de massas, aí incluído o exercício pleno do conjunto de direitos civis, políticos e sociais ${ }^{22}$.

De fato, a instituição do direito à informação como disciplina jurídica foi se efetivando na medida em que surgiu a necessidade de regulamentação e organização do exercício de um direito natural do homem, que passou a ser reconhecido com estas características nas leis fundamentais de diversos países. Trata-se do direito subjetivo à informação, "ao direito de informar e estar informado, ao direito de expressar ideias e de recebê-las, o germe e o objeto primário do direito à informação"23. Ao colocar a questão no âmbito do direito subjetivo, o autor afirma fazê-lo por não crer na exclusividade dos direitos pessoais como atribuições derivadas de leis estatais, que distribuem papéis a cada ator. Entende ele que o ser humano, enquanto tal, é

20 GENTILLI, Victor. Democracia de massas: cidadania e informação: estudo sobre as sociedades contemporâneas e o direito dos cidadãos à informação. 1995. 151f. Dissertação (Mestrado em Ciências da Comunicação) - Escola de Comunicações e Artes da Universidade de São Paulo, São Paulo, 1995. p. 148.

${ }^{21}$ Ibidem, p. 155.

22 Ibidem, p. 160.

${ }^{23}$ AREAL, Fernández Manuel. Introducción ao derecho de la información. Barcelona: ATE, 1977. p. 9. 
portador de valores e titular de direitos ainda antes de sua inserção em uma ordem jurídica determinada.

A propósito, Martinez ${ }^{24}$ estabelece a distinção entre os fundamentos subjacentes às expressões direito à informação e direito de informação. A primeira designa a mesma conotação apresentada anteriormente, relativa ao contexto dos direitos fundamentais do homem. A origem da segunda expressão reside no próprio reconhecimento legal, dentro do ordenamento jurídico, que contempla e configura o direito de informação. A autora entende, também, a informação como sendo um conjunto de formas, condições e atuações para fazer saber os elementos de conhecimentos, fatos, atividades, por meio de uma linguagem adequada e comunicável, em forma de palavras ou signos, sinais e símbolos. Este fazer saber, peculiar à informação inserida no processo da comunicação humana, apresenta as seguintes causas:

a) Uma causa material, que consiste na veracidade informativa;

b) Uma causa formal, expressa na comunicabilidade da informação, no que diz respeito à clareza e exatidão da linguagem empregada. Esta causa deve estar associada à intenção daquele que informa, bem como ao efeito objetivo da mensagem;

c) Uma causa eficiente, representada pelas condições de inteligibilidade da mensagem pelo receptor. Esta possibilidade de compreensão muitas vezes depende não apenas da capacidade deste, mas também das habilidades do informador;

d) Uma causa final, que se constitui na relação interpessoal estabelecida entre o informador e o informado. Esta causa é aquela que mais se coaduna com eixo essencial deste artigo, na medida em que se relaciona com as necessidades de aprimoramento humano, definindo a função social da informação para isso.

O princípio que se pretende enfatizar, o da emancipação, associado à questão do direito à informação, é aquele que se contrapõe ao princípio da pobreza política, considerada como tragédia histórica na mesma dimensão e profundamente associada à miséria socioeconômica. A dificuldade de formação de um povo capaz de gerir seu próprio destino e a dificuldade de institucionalização da democracia ${ }^{25}$ são as principais expressões desta realidade. Como solução,

\footnotetext{
${ }^{24}$ MARTINEZ, Angela Vivianco. Las libertades de opinión y de información. Santiago: Andrés Bello, 1992. p. 97.

${ }^{25}$ DEMO, op. cit., p. 54.
} 
propõe-se o exercício da cidadania como oportunidade da “prática da reivindicação, da apropriação de espaços, da pugna para valer os direitos do cidadão"26.

Mas a cidadania não necessita apenas da informação para efetivar-se. Ela depende também da ação do indivíduo e da sociedade, diante de tal fenômeno, o que irá determinar o tipo de informação a ser gerada e utilizada. Quanto mais conscientes forem as práticas sociais dos indivíduos, como reflexo de sua compreensão do que é sua realidade e de como ela deve ser, tanto mais voltada para o desenvolvimento e o bem-estar social será a informação produzida ${ }^{27}$.

Tal processo requer, entretanto, ressalta Barreto ${ }^{28}$, que os indivíduos tenham condições de elaborar a informação, enquanto insumo recebido, transformando-o em conhecimento esclarecedor e libertador, em benefício próprio e da sociedade onde vive. Em uma realidade fragmentada por desajustes sociais, econômicos e políticos, somente a disponibilidade ou a possibilidade de acesso à informação não basta, pois isso não implica no uso efetivo dela com possibilidade de promover a produção de conhecimento. Assim, a democratização da informação não depende apenas da implementação de programas para facilitar e aumentar o acesso a ela.

\section{AS FORMAS DE INTERAÇÃO ENTRE O MÉDICO E O PACIENTE E SUA INFLUÊNCIA NO EXERCÍCIO DA CIDADANIA}

Em nossa abordagem, focalizamos o papel desempenhado pela informação no processo em que indivíduos numa instituição hospitalar encontram-se em face do exercício de direitos fundamentais. Ou seja, o direito-meio, - a informação prestada ao paciente pelo profissional da saúde, que tem a capacidade de levar ao usufruto de direitos-fim, - direitos sociais e civis, e, por extensão, ao exercício da cidadania. Mas esta problemática tem, para a sua complexidade, a contribuição de um fator essencial e determinante para o processo exposto acima, - o das características da interação e, em geral, da comunicação entre o médico e o paciente.

\footnotetext{
${ }^{26}$ COVRE, op. cit., p. 10.

${ }^{27}$ ARAUJO, James Maxwell Fernandes. Uso da informação para cidadania na Rádio Educadora AM em São Luís. 2000. Dissertação (Mestrado em Ciência da Informação) - Faculdade de Estudos Sociais Aplicados Departamento de Ciência da Informação e Documentação, Universidade de Brasília, Brasília, 2000. p. 19.

${ }^{28}$ BARRETO, Aldo de Albuquerque. A questão da informação. Revista São Paulo em Perspectiva, Fundação Seade, São Paulo, v.8, n.4, 3-8, 1994. p. 5.
} 
Este encontro entre dois indivíduos tem sido marcado por diferenças, sobretudo de poder e pela subjugação de um sobre o outro. Com os efeitos sociais da revolução industrial, em particular o acelerado processo de urbanização que produziu os "grandes conglomerados humanos não-sadios" ${ }^{29}$, passaram a coexistir, a partir do século XIX, dois níveis de atendimento médico. Um deles, praticado em benefício dos ricos, era a medicina de beira de leito, bem distinto do outro, em que os pobres dispunham de precária e descontinuada assistência médica.

De qualquer forma, a relação era invariavelmente caracterizada pelas disparidades de experiências e, sobretudo, de informações de cunho científico, relativas à prática da medicina, o que determinava o nível de poder entre eles. Assim, restava aos pacientes a submissão a todas as decisões tomadas pelo médico, sem a possibilidade de questionamentos ou contestações em torno do diagnóstico, do tratamento e dos medicamentos prescritos. Esta era a principal característica do modelo paternalista de relação entre médico e paciente, onde as opiniões, sentimentos, crenças e contexto social deste último eram completamente ignorados.

Como alternativa a este padrão de relacionamento, Emanuel e Emanuel $^{30}$ mencionam o modelo informativo, o qual veio a atenuar a responsabilidade do médico. Enquanto esta é assumida em caráter absoluto no modo paternalista, não raro produzindo no profissional sentimentos de angústia e até de culpa, em face dos resultados obtidos, o modelo informativo permite a corresponsabilidade pelo tratamento. As decisões são tomadas pelo paciente e o médico passa a desempenhar o papel de transmissor de informações e de executor das ações propostas pelo paciente. E, em se tratando de uma relação de poder, este modelo se caracteriza mais pela acomodação do médico do que pela dominação do paciente, considerado como um cliente em uma relação de prestação de serviços ${ }^{31}$.

Se, por um lado, o modelo informativo conta com a aprovação de juristas, teóricos da bioética e da comunidade científica e política em geral, em particular pelo exercício do direito à informação, por outro, há também a necessidade de sua superação, conforme Caprara \& Franco:

\footnotetext{
${ }^{29}$ LANDMAN, Jaime. Medicina não é saúde: as diversas causas da doença e da morte. Rio de Janeiro: Nova Fronteira, 1983. p. 34.

30 EMANUEL, E; EMANUEL, L. Four models of the physician-pacient relationship. JAMA - Jornal of the American Medical Association, Washington DC: American Medical Association, v.16, 1992, Apud: EPSTEIN, Isaac (Org.). A comunicação também cura na relação entre médico e paciente. São Paulo: Argellara, 2005. p. 125.

31 EPSTEIN, Isaac (Org.). A comunicação também cura na relação entre médico e paciente. São Paulo: Argellara, 2005. p. 117.
} 


\begin{abstract}
Neste modelo informativo, o médico funciona como simples técnico, fornecedor de informações corretas para o paciente. A superação dos modelos paternalista e informativo significa a necessidade de assumir um processo de comunicação que implique na passagem de um modelo de comunicação unidirecional a um bidirecional, que vai além do direito à informação. Esse terceiro modelo, intitulado comunicacional, exige mudança de atitude do médico, no intuito de estabelecer uma relação empática e participativa que ofereça ao paciente a possibilidade de decidir na escolha do tratamento ${ }^{32}$.
\end{abstract}

Para $\operatorname{Remen}^{33}$, a saúde é hoje profundamente influenciada pela capacidade que cada indivíduo tem de formular e pôr em prática suas decisões. Desta forma, a própria natureza da vida contemporânea fez com que a escolha individual se tornasse o fator mais importante para a promoção e a preservação da saúde. O papel do médico e dos demais profissionais desta área é exatamente o de auxiliar nesse processo de escolha, por meio do compartilhamento de suas experiências, informações e conhecimentos. "O interesse do profissional não é o de apenas compreender os problemas físicos do paciente, mas também o de informá-lo das diversas opções para solucioná-los, certificando-se que essas opções e suas consequências foram totalmente compreendidas" 34 .

Tal nível de compreensão vem ao encontro do que Veatch ${ }^{35}$ denominou de modelo contratualista, onde o médico assume a responsabilidade por todas as decisões tomadas no contexto da aplicação das técnicas, mas o paciente também tem a oportunidade de participar efetivamente do processo decisório. O encontro entre médico e paciente, no modelo contratualista, se dá a partir da negociação, do compromisso recíproco e do respeito às particularidades pessoais de cada paciente. Esta concepção de relacionamento interpessoal representa uma proposta de ruptura com os modelos paternalista e informativo, pois consiste em novas formas de interação, não apenas de médicos e pacientes entre si, mas também entre os profissionais e a sociedade.

\footnotetext{
32 CAPRARA, Andrea; FRANCO, Anamélia Lins e Silva. A relação paciente-médico: para uma humanização da prática médica. Cadernos de Saúde Pública. Rio de Janeiro, vol.15, n.3, p. 647-654. Jul/Set. 1999. p. 651.

${ }_{33}$ REMEN, Rachel Naomi. O paciente como ser humano. São Paulo: Summus, 1993. p. 149.

${ }^{34}$ Ibidem, p. 152.

${ }^{35}$ VEATCH, R. M. Models for ethical medicine in a revolutionary age. Hastings Center Report, New York: 1972, v. 2, p. 5-7. Apud: CARPIGIANI, Berenice. A arte e a técnica da comunicação na saúde: um estudo das estruturas de comunicação presentes na relação entre o médico e seu paciente. 2007. 224f. Tese (Doutorado em Comunicação Social) - Programa de Pós-Graduação em Comunicação Social, Universidade Metodista de São Paulo, São Bernardo do Campo, 2007. p. 75.
} 
A necessidade de superação da relação de dependência e submissão, que caracteriza o encontro, é, eventualmente, defendida por médicos, quando se tornam pacientes e têm a oportunidade de vivenciar o outro referencial, - o da experiência do sofrimento como parte integrante da relação entre médico e paciente. Depoimentos como o do neurologista Oliver Sacks, que, ao fraturar a perna, percebeu (...)

(...) a sistemática despersonalização que se vive quando se é paciente. As próprias vestes são substituídas por roupas brancas padronizadas e, como identificação, um simples número. A pessoa fica totalmente dependente das regras da instituição; se perdem muitos dos seus direitos, não se é mais livre ${ }^{36}$.

Essa condição relatada por Sacks ilustra um importante aspecto da organização da sociedade, lembrado por Marilena Chaui ${ }^{37}$ em sua argumentação sobre a ideologia do discurso competente. Para ela, o processo de burocratização de todas as esferas da vida social, inclusive das instituições dentro da esfera da saúde pública e a utilização do discurso da organização representam um eficaz instrumento a serviço da ideologia, com a finalidade de ocultar a total ou quase total interferência do Estado na sociedade civil.

Tal processo integra o mecanismo de ocultação ou dissimulação sistemática da relação de dominação presente na interação do médico com o paciente, em razão da “crença em uma ratio administrativa ou administradora, tal que dirigentes e dirigidos pareçam ser comandados apenas pelos imperativos racionais do movimento interno à organização" ${ }^{38}$. Burocratização e organização, explica a autora, trazem consigo certos pressupostos, que se manifestam por meio de algumas determinações tais como: a crença na realidade em si, de modo que a racionalidade dos meios de ação invalida de forma automática todo movimento questionador acerca da racionalidade dos fins da ação; a existência de um sistema de autoridade fundado na hierarquia; e a garantia do reconhecimento recíproco dos membros de uma estrutura burocrática enquanto superiores e subalternos.

\footnotetext{
${ }^{36}$ CAPRARA; FRANCO, op. cit., p. 650.

${ }^{37}$ CHAUÍ, Marilena. Cultura e democracia. São Paulo: Cortez, 1989. p.9.

38 Ibidem, p. 9.
} 
Mais otimista, John Parry, ainda na década de 60, já apresentava argumentos que expressavam confiança na evolução da relação entre médico e paciente, comparável à que progressivamente aconteceu na interação entre professores e alunos. "No passado, físicos e mestres eram investidos de uma autoridade relativamente imune à contestação. Hoje em dia, sua autoridade precisa ser confirmada por uma competência demonstrável"39. Da mesma forma, completa ele, o status de paciente se elevará gradualmente de uma posição de obediência incondicional a uma posição de esforço contributivo.

\section{CONCLUSÃO}

É um dos pontos pacíficos nas abordagens sobre cidadania, que ela será legítima, consistente e duradoura, apenas se tiver a participação consciente e efetiva dos indivíduos em sociedade. Esta é a condição essencial para a autonomia, entendida aqui como o atributo de cidadãos que criam e desenvolvem projeto próprio de desenvolvimento. Sendo assim, não é plena a cidadania concedida e sem a participação ativa dos seus principais beneficiários em sua construção e implementação.

Desta forma, considerando o tema específico deste artigo, voltado para a análise da peculiar situação do encontro entre médico e paciente, convém reiterar que ela implica necessariamente no exercício de direitos sociais e civis, por tratar-se de interação social e atendimento no campo da saúde, e também em decisões a serem tomadas em relação ao corpo de um indivíduo enfermo. Diante desta constatação, cabe observar as condições sob as quais este direito social é exercido e se o encontro entre o médico e seu paciente ocorre de maneira em que este último possa, ao mesmo tempo, receber a atenção e o tratamento necessários, e ainda ter sua individualidade, desejos e opiniões respeitadas.

Portanto, o direito à informação, como direito que leva à obtenção de outros, não poderá ser efetivamente exercido a partir da postura passiva do paciente à espera das iniciativas do profissional da saúde. É indispensável sua real participação, o que depende também da

39 PARRY, John. Psicologia da comunicação humana. Tradução de Octavio Mendes Cajado. São Paulo: Cultrix, 1967. p. 170. 
disposição e do nível de compreensão do médico acerca da importância do modelo dialógico para a promoção e o desenvolvimento da saúde.

\section{REFERÊNCIAS}

ARAUJO, James Maxwell Fernandes. Uso da informação para cidadania na Rádio Educadora AM em São Luís. 2000. 93f. Dissertação (Mestrado em Ciência da Informação) - Faculdade de Estudos Sociais Aplicados - Departamento de Ciência da Informação e Documentação, Universidade de Brasília, Brasília, 2000.

AREAL, Fernández Manuel. Introducción ao derecho de La información. Barcelona: ATE, 1977. $120 \mathrm{p}$.

BARRETO, Aldo de Albuquerque. A questão da informação. Revista São Paulo em Perspectiva, Fundação Seade, São Paulo, v.8, n.4, p. 3-8, 1994.

BORDENAVE, Juan E. Diaz. Além dos meios e mensagens - introdução à comunicação como processo, tecnologia, sistema e ciência. Petrópolis: Vozes, 1993. 110 p.

BORDENAVE, Juan E. Diaz. O que é comunicação. São Paulo: Brasiliense, 1985. 106 p.

BRASIL. Constituição Federal. Brasília: Senado Federal, 1988. Disponível em <http://www.planalto.gov.br/ccivil_03/constituicao/constituicaocompilado.htm> Acesso em 5 out. 2015.

CAPRARA, Andrea; FRANCO, Anamélia Lins e Silva. A relação paciente-médico: para uma humanização da prática médica. Cadernos de Saúde Pública. Rio de Janeiro, vol.15, n.3, p. 647-654. Jul/Set. 1999.

CHAUÍ, Marilena. Cultura e democracia. São Paulo: Cortez, 1989. 309 p.

Conselho Federal de Medicina - Código de Ética Médica: resolução CFM n 1.246/88 - Código de Processo Ético-Profissional: resolução CFM n 1.617/01 - Brasília: CFM, 2001.

COVRE, Maria de Lourdes Manzini. O que é cidadania. São Paulo: Brasiliense, 1993. 78 p. 
DALLARI, Sueli Gandolfi. O direito à saúde. Revista de Saúde Pública. São Paulo, 22(1):57-63, 1988.

DEMO, Pedro. Cidadania e emancipação. Revista Tempo Brasileiro, Rio de Janeiro, 100, p. 5372, jan./mar., 1990.

EMANUEL, E; EMANUEL, L. Four models of the physician-pacient relationship. JAMA - Jornal of the American Medical Association, Washington DC: American Medical Association, 1992, v.16. Apud: EPSTEIN, Isaac (Org.). A comunicação também cura na relação entre médico e paciente. São Paulo: São Paulo: Argellara, 2005. 206 p.

EPSTEIN, Isaac (Org.). A comunicação também cura na relação entre médico e paciente. São Paulo: Argellara, 2005. 206 p.

FREIRE, Isa Maria. Informação - consciência possível - campo: um exercício com construtos teóricos. Ciência da Informação, Brasília, v.24, n.1, p.133-142, jan-abr 1995.

GAUDERER, Christian. Os direitos do paciente: cidadania na saúde. Rio de Janeiro: Record, 1998. $247 \mathrm{p}$.

GENTILLI, Victor. Democracia de massas: cidadania e informação: estudo sobre as sociedades contemporâneas e o direito dos cidadãos à informação. 1995. 151f. Dissertação (Mestrado em Ciências da Comunicação) - Escola de Comunicações e Artes da Universidade de São Paulo, São Paulo, 1995.

LANDMAN, Jaime. Medicina não é saúde: as diversas causas da doença e da morte. Rio de Janeiro: Nova Fronteira, 1983. 247 p.

LUZ, Madel Terezinha. As conferências nacionais de saúde e as políticas de saúde da década de 80. In: GUIMARÃES, Reinaldo; TAVARES, Ricardo (Orgs.). Saúde e sociedade no Brasil, anos 80. Rio de Janeiro: Relume-Dumará/IMS-UERJ, 1994. 256 p.

MARSHALL, T. H. Cidadania, classe social e status. Tradução de Meton Porto Gadelha. Rio de Janeiro: Zahar, 1967. 215p.

MARTINEZ, Angela Vivianco. Las libertades de opinión y de información. Santiago: Andrés Bello, 1992. 103 p.

MELO, José Marques de. Comunicação: direito à informação. Campinas: Papirus, 1986. 151 p. 
PARRY, John. Psicologia da comunicação humana. Tradução de Octavio Mendes Cajado. São Paulo: Cultrix, 1967. 267 p.

REMEN, Rachel Naomi. O paciente como ser humano. São Paulo: Summus, 1993. 221 p.

SARACEVIC, Tefko. Ciência da informação: origem, evolução e relações. Perspectivas em Ciência da Informação, Belo Horizonte, v.1, n.1, p.41-62, jan./jun., 1996.

URDANETA, Iraset Páez. Gestión de la inteligencia, aprendizaje tecnológico y modernización del trabajo informacional: retos y oportunidades. Caracas: Instituto de Estudios del Conocimiento de la Universidad Simon Bolivar - Consejo Nacional de Investigaciones Cientificas y Tecnologicas, 1992. 194 p.

VEATCH, R. M. Models for ethical medicine in a revolutionary age. Hastings Center Report, New York: 1972, v. 2, p. 5-7. Apud: CARPIGIANI, Berenice. A arte e a técnica da comunicação na saúde: um estudo das estruturas de comunicação presentes na relação entre o médico e seu paciente. 2007. 224f. Tese (Doutorado em Comunicação Social) - Programa de Pós-Graduação em Comunicação Social, Universidade Metodista de São Paulo, São Bernardo do Campo, 2007.

Recebido em: 28.08.2015 / Revisões em 02.10.2015 Aprovado em: 15.10.2015 